\title{
EL CONTROL DEL «FICCIONAL»: ALCIDES ARGUEDAS Y EUCLIDES DA CUNHA
}

POR

IAVIER SANJINES C.

University of Minnesota

Tejido que se despliega en distintos planos y direcciones, la literatura de Occidente es un «todo» de relaciones de afinidad y de contradicción, de contiguiidad y también de separación. Siempre en movimiento, la de Occidente es literatura en expansión. Por eso aparece, como producto de la conquista y de la colonización, la literatura iberoamericana, en sus dos grandes ramas: la portuguesa y la castellana. Aunque las literaturas brasileña e hispanoamericana siguen una evolución independiente, ambas presentan, sin embargo, analogías y similitudes que la crítica literaria debe investigar. $Y$ porque la literatura iberoamericana no es un mero conjunto de obras, sino las relaciones entre esas obras, cada una de ellas es una respuesta, declarada o tácita, a otra obra escrita por un predecesor o un contemporáneo y una prolongación hacia un imaginario descendiente. Euclides da Cunha leyó con provecho a Domingo Faustino Sarmiento, y las ideas del educador argentino no pasaron inadvertidas para Alcides Arguedas, cuyo Pueblo enfermo las registra como telón de fondo de su argumentación racional. De este modo, nuestro trabajo quiere explorar en Los Sertones y en Pueblo enfermo ese tejido de relaciones desde un punto de vista específico: el viaje del control del «ficcional».

La temática del control del «ficcional» es un capítulo nuevo y poco estudiado por la crítica literaria. Debemos, sin embargo, al crítico brasileño Luiz Costa Lima un sugerente tratamiento del problema en su libro $O$ controle do imaginário, donde el autor muestra cómo el advenimiento 
de la razón moderna contribuyó a la represión del ámbito de la ficción ${ }^{1}$. En efecto, al desarrollar las condiciones bajo las cuales nace la idea de que la ficción literaria es engaño y fingimiento, susceptible, por tanto, al control o veto del discurso histórico, Costa Lima arguye que la primacía de la razón por sobre la imaginación se quiebra con el romanticismo europeo, escuela literaria que rescata a la ficción y la libera del control o veto que la acompañaba. Aunque el recorrido de este veto del «ficcional» puede parecer ajeno a los efectos inmediatos de nuestro trabajo, proponemos aquí relacionar dos aspectos complementarios del estudio de Costa Lima, los que nos serán muy útiles para la ubicación de la problemática tratada tanto en Los Sertones, de Euclides da Cunha, como en el Pueblo enfermo, de Alcides Arguedas: por una parte, que la crisis del pensamiento analógico y el advenimiento de la subjetividad han incidido en la manera desconfiada con que el discurso histórico tradicionalmente concibe al discurso «ficcional» imaginario; por otra, que relegando al «ficcional» a su función meramente ornamental, desprovista de veracidad, el discurso histórico, teológico o sociológico, lo domina y controla con afán moralizador o utilitario.

Próximo a los argumentos del libro de Costa Lima, Michel Foucault muestra en «La prosa del mundo», capítulo segundo de Las palabras y las cosas, que la analogía, uno de los cuatro principios en que se funda la semejanza ${ }^{2}$, desempeñó, hasta el siglo xvI, un rol primordial en el saber de la cultura occidental. Para el filósofo francés, fue ella la que guio la exégesis e interpretación de los textos, la que organizó el juego de los símbolos, permitió el conocimiento de las cosas visibles e invisibles y dirigió el arte de representarlas. Teatro de la vida o espejo del mundo, he ahí el rótulo bajo el cual la analogía se introduce en el lenguaje y formula su derecho a hablar. De este modo, la analogía, expresión de la correspondencia entre el mundo celeste y el terrestre, no conoce de escisión alguna entre palabra e historia. La alegoría, por ejemplo, que asume la comunicación poética de la perfecta alianza entre palabra e historia, descubre sólo semejanzas, hasta convertir al universo en un tejido de relaciones y equivalencias. Por eso la Comedia, de Dante, la obra más acabada y plena del pensamiento analógico medieval, es un código de alegorías circulares en las

1 Luiz Costa Lima, O controle do imaginário. Razão e imaginação no Ocidente (São Paulo: Editora Brasiliense, S. A., 1984).

${ }^{2}$ Michel Foucault, Las palabras y las cosas, 10." ed., traducción de Elsa Cecilia Frost (México: Siglo XXI Editores, S. A., 1978). Los otros principios son la «convenientia» o semejanza del lugar en que la naturaleza ha puesto las cosas; la «aemulatio», especie de conveniencia libre de la ley del lugar, y las «simpatías», que juegan en estado libre en las profundidades del mundo. 
que el mensaje del poeta, la Comedia, se descifra en otro mensaje, el libro del Exodo, que a su vez se explicita en otro: el Evangelio. Así, por el principio de la analogía, la correspondencia entre palabra e historia es perfecta.

La crisis de este sistema de pensamiento, que Costa Lima explica con la ayuda de algunos estupendos estudios sobre la lenta maduración de la experiencia de la subjetividad ${ }^{3}$, aparece en los siglos XIV y XV, particularmente con el surgimiento del individuo como entidad psicológica, y culmina a principios del siglo XVII, momento en el que el pensamiento deja de moverse dentro del elemento de la semejanza. No es que ésta desaparezca, sino que la nueva episteme de la cultura occidental, en el sentido en que Foucault la concibe, obliga a la sustitución de la jerarquía analógica por el análisis. Al entrar en crisis el sistema global de correspondencia, la semejanza queda sometida a la prueba de la comparación y la unidad a la serie de diferencias. En otros términos: el discernimiento impone a la comparación la búsqueda primera y fundamental de la diferencia, y ya que conocer es discernir, las palabras y la historia van a quedar separadas las unas de la otra. A partir de ahora, el lenguaje se retira del centro de los seres, se torna opaco y difuso, deja de formar parte de los signos y de las formas de la verdad. El lenguaje no es ya la signatura impuesta a las cosas desde el fondo de los tiempos. La verdad, por su parte, sólo encuentra su manifestación y su signo en la percepción de lo evidente y de lo definido.

Don Quijote es la primera de las obras modernas en que se mueve la nueva episteme: la escritura ha dejado de ser la prosa del mundo; las semejanzas y los signos han roto su viejo compromiso; las similitudes engañan, llevan a la visión y al delirio; las cosas permanecen obstinadamente en la realidad irónica de no ser más lo que son; las palabras vagan a la aventura, sin contenido, sin semejanza que las llene. Por eso, si la locura de Don Quijote confunde la percepción de lo cotidiano con el mundo de lo imaginario, borrando las fronteras entre ambos, Sancho, fiel exponente de la razón perceptiva, busca alejar a su señor de los riesgos de la locura y le aconseja conducirse según los principios de la verosimilitud y del decoro. Y es la razón de Sancho que, desterrando a la imaginación, tiende ya la línea divisoria que la Edad Moderna reforzará entre historia y fic-

${ }^{3}$ Costa Lima se refiere a los siguientes trabajos: Hans Ulrich Gumbrecht, «Erszählen in der Literatur/Erszählen im Alttahg», en Erszählen im Alttahg (Francfort: Suhrkamp Verlag, 1980); Howard Bloch, Medieval french literature and law (Berkeley: University of California Press, 1977); Paul Zumthor, Langue, texte, énigme (París: Seuil, 1975); Jacques Le Goff, La Naissance du purgatoire (París: Gallimard, 1981). Para el análisis de estas obras, véase el primer capítulo de $O$ controle do. imaginário, pp. 11-19. 
ción. Mientras aquélla será exaltada como verdad, ésta quedará recluida al ámbito de la falsedad y de la mentira.

Las negaciones sucesivas de la subjetividad - que en las antinomias del pensamiento burgués se llama filosofía- se dan incluso antes de la aparición de la novela de Cervantes; en efecto, los libros de caballería, ajenos a las teologías alegóricas, son vistos como obras de diversión y pasatiempo, no como representación de la historia del hombre, sino como relato de su insensata aventura. Puesto que la palabra, el lenguaje, ya no posee la clave del mundo, es una palabra vana, loca, sospechosa, que debe ser controlada y vetada. Alejada del pensamiento analógico, la subjetividad opera ahora en sentido inverso: subraya el abismo entre lo real y lo imaginario, entre la palabra y la historia. Por eso el aparato estatal y sus clases dominantes deben controlarla y, en cierto sentido, desplazarla.

Cuando los libros de caballería se propagan en el Nuevo Mundo, hecho que es verificado por el propio Bernal Díaz del Castillo casi a fines del siglo XVI, chocan inmediatamente con el control ejercitado por las autoridades civiles y eclesiásticas, temerosas de que estos libros profanos subviertan las buenas costumbres de la población colonizada. Puesto que, para el aparato represivo colonial, el hombre común era ya incapaz de distinguir entre la verdad y el deleite, las autoridades resuelven combatir lo segundo porque lo juzgan perturbador de la conducción moral de la cotidianidad. De este modo, el control del «ficcional» se da directamente en los decretos reales. Entre los muchos documentos recogidos por Irving Leonard en su obra Books of the brave, resaltan aquellos en los que la Corona se preocupa por vicios y malas costumbres que indígenas y pobladores en general pueden adquirir de la lectura de «mentirosas historias» y de «libros de historias vanas», compuestos sin tomar en cuenta las Sagradas Escrituras y los libros de los «doctores santos» ${ }^{4}$. Instrucciones reales como las transcritas por Leonard tuvieron consecuencias en el desarrollo controlado del intelecto colonial. En De la conquista a la independencia, Mariano Picón Salas emite juicios directamente relacionados con los documentos expuestos por el historiador norteamericano. Afirma Picón Salas: «Obligado a callarse por los decretos reales y la policía de la Inquisición, el intelecto colonial, a quien no se le permite escribir novelas ni historias de la gente indígena, se evadirá por los tortuosos meandros de la prosa barroca ${ }^{5}$; luego añade: «El siglo no consiente, por lo menos en las alejadas colonias americanas, mayor libertad al escritor. $\mathrm{Y}$ esta ten-

\footnotetext{
"Irving Leonard, Books of the brave (Nueva York: Gardian Press, 1964).

${ }^{5}$ Mariano Picón Salas, De la conquista a la independencia, 5. ${ }^{\mathrm{a}}$ ed. (México: Fondo de Cultura Económica, 1975), p. 119.
} 
dencia represiva o escrupulosa acaso nos explique por qué el realismo narrativo español, cuyo más maduro fruto fue la novela picaresca, quedó en América en estado larvario» ${ }^{6}$.

Navegando en el piélago de obras de lenguaje y títulos estrafalarios que la erudición produce en las capitales virreinales, el historiador de la cultura puede advertir en la literatura barroca una forma críptica, sumamente trabajada y enrevesada por dos razones: porque no se tiene nada que decir o porque hay que precaverse de todo peligro en la más compleja red de las formas. La literatura parece constituirse como un arte de la palabra autónoma, de retórica ornamental, donde todo se sacrifica a la musicalidad, al canto y a la extrañeza. Así, la erudición barroca impone nuevamente el control vertical de modelos clásicos de elocuencia y sabiduría que hacen de la literatura una nueva forma alegórica de la verdad. En efecto, entre la realidad y el arte se vuelve a interponer la alegoría no tanto como correspondencia entre los mundos celeste y terrestre, en que la empleara la Edad Media, sino para alumbrar con una luz nueva, más artificial, el confuso campo de la realidad. Decimos artificial, porque, al tono general de su cultura que imponía la metrópoli, el medio americano agrega todas las complejidades que surgen del trasplante: privilegio de una minoría letrada y ausente de la comprensión de las masas indígenas o mestizas, el trabajo intelectual tiene en las colonias un carácter exclusivamente críptico. Lo bizarro y lo peregrino sirven a este juego, a la vez cortesano y erudito, que entretiene los ocios de la minoría. La estructura del nuevo estilo marca la frontera precisa entre una literatura principalmente activa, rica en hechos y acciones como había sido la del siglo de la conquista, y otra en que la acción cede el paso a la contemplación, el contenido a la forma; típica literatura de una sociedad que se ha hecho más sedentaria y urbana; que valora más el colorido, la musicalidad o la agudeza. De la Antigüedad clásica, que vuelve a controlar el «ficcional», se prefiere en ese momento no a Horacio y Virgilio, sino la imitatio del preciosismo sin contenido de Ovidio, alternando lo lírico con la lectura familiarizada de la Biblia y los Evangelios. Todo esto lleva a Picón Salas a afirmar que el intelecto colonial se evade por los tortuosos meandros de la prosa barroca, al servicio de la centralización política. De este modo, la imitatio actúa como instrumento de conciliación entre las pretensiones de verdad postuladas por la Iglesia y el dirigismo político, centralizador, del aparato estatal barroco. Principio regulador paralelo a las instituciones políticas, la imitatio impide que la ficción se torne salvaje, incontrolable, incapaz de respetar jerarquías. En un mundo en que no se leen novelas y en el que

${ }^{6}$ Ibid., p. 120. 
hasta los romances de caballería están prohibidos, se prefiere el ornamento de lo falsamente deleitable un poco por ingenuidad y otro tanto por falta de espíritu crítico.

Por eso, alcanzada la independencia, la ruptura con España significará también el rechazo de la función ornamental del lenguaje, desprovista de veracidad y de persuasión. El veto del «ficcional», tan claro en el discurso moralizador español, se aclimata en América independiente, aunque ahora por razón diferente. Al romper con la tradición española, la literatura de la Independencia se aparta de lo barroco, de lo ornamental, y opta por el control horizontal del «ficcional», control que da primacía al culto de lo pragmático, de la ceñida observación de la realidad, de las costumbres locales y de sus diferentes regiones. Es ahora la razón cotidiana la que domina la ficción, a través de un racionalismo ético que purga al «ficcional» de todo aquello que amenaza su honesto entendimiento. Combinando la verosimilitud con el decoro, la razón pragmática de los próceres y profetas independentistas condena la imaginación como enemiga de lo cotidiano. La ficción permanecerá, pues, como algo sospechoso en un continente en que nada existe y todo está por hacerse. Por ello, la urgencia de resultados prácticos hará que el intelectual subordine la literatura a la primacía del documento histórico y que la temática perceptora y cientificista del discurso pragmático domine al discurso «ficcional» imaginario.

Tanto en el Discurso de incorporación a la sociedad literaria como en el Dogma socialista, José Victorino Lastarria y Esteban Echeverría desarrollan los puntos programáticos de una literatura nacional útil y progresista en pro de la regeneración liberal de la sociedad. De este modo, la razón pragmática del «americanismo literario» propone una utopía social asociada con el librecambismo económico y con el liberalismo político ${ }^{7}$. De igual manera, la retórica desecha ahora la semejanza y la sustituye por la diferenciación. Ser "propio» es «no ser español»; en consecuencia, la «ley del ser» responde a las exigencias nacionales de abandonar todo resquicio de las costumbres heredadas de la colonia. Facundo, la conocida obra de Domingo Faustino Sarmiento, es otro ejemplo de este discurso pragmático que, a través de la detallada observación de la realidad empírica, forja hipótesis que, luego de ser comprobadas, permiten a su autor plantear el modelo racional utópico de la democracia liberal republicana. Partiendo de la premisa de que la unidad es la ley natural del ser argentino, la República, bárbara o civilizada, marcha visiblemente a la unidad de gobierno

${ }^{7}$ Véase Hernán Vidal, Literatura hispanoamericana e ideología liberal: surgimiento y crisis (Buenos Aires: Ediciones Hispamérica, 1976). Véase también nuestro trabajo «E1 " americanismo literario" como ideología dominante en la literatura hispanoamericana», en Hipótesis, 18 (1983), pp. 177-197. 
a que su superficie llana, su puerto único, la condenan. Puede llamarse Federal o Republicana, pero todo va encaminándose a la unidad absoluta. Así, el proyecto pedagógico pragmático refuerza el liberalismo como nuevo sistema político, pero deja intacta la estructura social de los herederos directos de la colonia: hacendados, comerciantes, militares y funcionarios.

Para Sarmiento, quien no dispone todavía de la teoría cientificista de los atavismos biológicos; la naturaleza determina al hombre, pero éste puede transformarla. Esto se demuestra por el hecho de que las poblaciones nativas, sometidas a la barbarie y al atraso, pueden recibir las luces de la civilización. La parte propiamente narrativa de la obra de Sarmiento relata no solamente el paso del héroe épico, de la esfera provincial a la nacional, sino también la metamorfosis que Facundo Quiroga, el gaucho malo, esencia de lo americano, va sufriendo en la medida en que se aproxima a la capital. Llegado Facundo a Buenos Aires, el poder educa: su conducta es mesurada, su aire noble e imponente. Este acontecimiento individual puede también hacerse extensivo a la colectividad bárbara, porque, echándose las campañas sobre las ciudades, se han hecho ciudadanos los gauchos y simpatizado con la causa de las ciudades.

Se ve entonces cómo el método experimental controla la imaginación, enfrentándola a la realidad cotidiana para captar sus principios fundamentales. Consecuentes con esta visión de las cosas, las doctrinas políticas surgirían de la realidad concreta. Como beneficio definitivo de la nueva edificación fílosófica cientificista, se produciría la unidad espiritual de las siguientes generaciones, las que gozarían de un común marco de referencia ideológica. Lograda la unidad espiritual del pueblo, actuando éste con clara voluntad colectiva, terminaría el desorden y la anarquía. Pero esta utopía se derrumba a fines del siglo xIx, cuando la inteligentsia americana, al cambiar el antifaz liberal por la careta positivista, cae también en cuenta de que el verdadero nombre de nuestra democracia es caudillismo y que nuestro liberalismo es autoritarismo.

Ahora el positivismo, doctrina a que conduce el liberalismo romántico, capta las dislocaciones entre ideología y materialidad social, y la confianza en conceptos abstractos como fraternidad, igualdad, libertad, cede ante el criterio determinista de lo verificable. En última instancia, lo único verificable, desde este nuevo punto de vista, es la ley de supervivencia del más fuerte y la desaparición del más débil. Bajo este influjo determinista, él control del «ficcional» opera a través de la mirada homogéneamente trágica de la naturaleza americana y de las razas que pueblan su territorio. Si antes la naturaleza era factor de unidad, ahora es factor de disociación. $\mathrm{Y}$ es que el cientificismo de la sociología biológica se echa a andar con el determinismo selectivo de Los Sertones, de Euclides da Cunha, y con el 
fatalismo corrosivo del Pueblo enfermo, de Alcides Arguedas. Mediante el deslinde de los tipos humanos favorables y desfavorables en el proceso de formación de la identidad cultural, ambos autores controlan al «ficcional» por medio de la metáfora de la sangre. De esta manera, anclados en lo biológico, los dos escritores elaboran una teoría de las razas como factor determinante de la historia y de la mayor o menor capacidad de aquéllas para adaptarse a las exigencias de la civilización.

Al realizar el examen comparativo de Los Sertones y Pueblo enfermo, el investigador se enfrenta casi de inmediato con una duda de no fácil resolución: ¿cómo estudiar ambos libros desde el punto de vista de la ficción? Los Sertones, al igual que el Facundo, de Sarmiento, rompe con los moldes tradicionales de los géneros literarios. Clasificarlo, como tendenciosamente se ha propuesto durante mucho tiempo, entre las novelas, equivale a caer en error tan grave como incluirlo entre los libros de historia. Los Sertones es un todo complejo: biografía, novelesca por su interés, de Antônio Conselheiro; poema descriptivo del medio ambiente sertanejo; movida, dramática historia de la guerra de Canudos; ensayo sociológico de los tipos humanos que pueblan el territorio brasileño, y, en última instancia, formidable e irritante alegato contra una República ciega ante la realidad que vive el país.

Publicada en 1902, cinco años después de concluida la guerra de Canudos, la obra de Euclides da Cunha es, por cierto, determinista, lo que se evidencia en las tres partes en que se divide el libro, tituladas «La tierra», "El hombre» y «La lucha». Euclides intenta demostrar que el medio ambiente natural (geografía y clima) determina la constitución de los agrupamientos humanos, mientras el ambiente social que incluye la raza determina el tipo psicológico y el comportamiento colectivo. De los cruzamientos raciales entre blancos e indios, en el aislamiento del desierto, el resultado sería el mestizo, de temperamento inestable, incapaz de construir una cultura. En términos generales, y guardando las diferencias que puntualizaremos en el recorrido del análisis, esta explicación determinista de Los Sertones aparece también en la obra de Alcides Arguedas.

Al igual que en el Perú, la derrota frente a Chile lleva a la intelectualidad boliviana a buscar las causas que originaron el fracaso de la guerra del Pacífico. En el camino de autoanálisis, el positivismo brinda el arsenal ideológico con el cual toda una generación busca explicar la derrota. Nicomedes Antelo y Gabriel René Moreno primero y Alcides Arguedas des- 
pués pretenden interpretar la sociedad a partir de la geografía y la raza. En Pueblo enfermo, publicado en 1909, las desoladas llanuras de Bolivia y el hombre que las habita son expresión de su dura realidad. Aquí, dice Arguedas, todo lo que nace del hombre se transforma en ficción malsana, donde la raza indígena, poco atrayente y sin dotes de inteligencia, no es sino negación del hombre; la blanca, no llevando pura su sangre, ha degenerado en la indisciplina mental y moral, y la mestiza, naturalmente atávica, explica racionalmente la decadencia social.

Si Los Sertones y'Pueblo enfermo más que obras literarias son ensayos sociológicos de explicación de la realidad, ¿cómo sujetarlos al análisis del control del «ficcional»? Para el caso de Los Sertones, Luiz Costa Lima ha visto, en su mencionado $O$ controle do imaginário, la naturaleza dispar y problemática de las diferentes partes de la obra ${ }^{8}$. «La tierra» y «La lucha» muestran diferencias entre la realidad y lo narrado, produciendo así un discurso imaginario en el que el proceso de identificación activa con el medio ambiente natural se distancia de los criterios de verdad o falsedad propios al discurso pragmático del cientificismo. De este modo, la naturaleza y la lucha social no son descritas por el narrador desde un prisma aséptico, libre del germen de la invención imaginaria, como lo exigiría el ideal científico, sino, por el contrario, a través de una visión trágica, agónica, de los movimientos sociales. Al establecer la distinción entre el medio físico y social como fuentes de la mimesis y la forma trágica en que ambos son mimetizados, estas dos partes de Los Sertones no se someten al criterio de la semejanza, sino que tienden a la función diferencial del discurso de la ficción. En «El hombre», sin embargo, el control del imaginario se echa a andar con la reproducción y copia de los conceptos etnocéntricos, ajenos a la mimesis, del sociologismo biológico. La mimesis literaria queda entonces dominada. $Y$ porque el etnocentrismo domina a la visión trágica de la naturaleza y del destino humano, porque el esquema teórico evolucionista hace lo propio con la organización imaginaria, resulta inadecuado hablar de Los Sertones como ficción, debiendo entendérselo como discurso sociológico de la realidad.

El problema de la identificación de la mimesis en la obra de Euclides da Cunha se torna más simple en el Pueblo enfermo, de Arguedas. En éste es claro que la mimesis está totalmente dominada por el procedimiento determinista del fatalismo casi mecánico entre hombre y medio ambiente. Puesto que Arguedas no busca imitar diferencialmente la realidad, sino copiarla y reproducirla, la razón pragmática controla absolutamente la imaginación. En Pueblo enfermo, el control del «ficcional» está incluso plan-

${ }^{8}$ Op. cit., p. 238. 
teado explícitamente en las afirmaciones del escritor sobre la función de la literatura. Como se verá en la parte final de este trabajo, la función moralizadora de Pueblo enfermo encubre la postura pragmática del control del «ficcional», postura que, por otra parte, también aparece en la novela $\mathrm{y}$ en las memorias intimas del autor. Por ahora, merece destacarse que, a pesar de las semejanzas etnocéntricas de ambas obras, la visión trágica, agónica, de la narración mimética de Los Sertones no puede ser confundida con el determinismo mecanicista de Pueblo enfermo.

En Euclides hay la lectura previa del Facundo, de Sarmiento. Pero incluso aquí se dan diferencias nada desdeñables. En Facundo, el narrador omnisciente va buscando los mejores puntos de observación. Ellos permiten presentar el panorama general de la naturaleza y de la población. De la observación detallada de la realidad, el narrador formula la hipótesis de la unidad como la ley primordial del ser argentino. Luego prueba dicha hipótesis a través de secuencias narrativas, que van de lo privado hasta lo nacional. Concluye, por último, con el programa ideológico liberal, el cual opera como modelo ideal de racionabilidad.

En Los Sertones, la propia observación de la realidad y de los tipos humanos que pueblan el territorio nordestino da lugar a la explicación del sertanejo como subcategoría étnica superada, ideal de explicación científica con la que Euclides pone inconscientemente en entredicho el método evolucionista admitido como punto de partida. Veamos cómo se da esta crisis.

En la «Nota preliminar» de la obra, Euclides, convencido del evolucionismo biológico, parte del supuesto de que ciertas subrazas están predestinadas a desaparecer por contacto con razas superiores:

Intentamos esbozar, aunque sea pálidamente, ante los futuros historiadores, los trazos actualmente más expresivos de las subrazas sertanejas del Brasil. Lo hacemos porque su inestabilidad, debida a factores múltiples y diversamente combinados, aliada con las vicisitudes históricas y la deplorable situación mental en que se encuentran, las vuelven tal vez efímeras, destinadas a una próxima desaparición ante las crecientes exigencias de la civilización... La civilización avanzará por los sertones arrastrada por esa implacable fuerza motriz de la historia que Gumplowicz, superior a Hobbes, entrevió, con visión genial, en la destrucción inevitable de las razas débiles para las razas fuertes ${ }^{9}$.

La «fuerza motriz de la historia», a la que alude Euclides, viene determinada por la geografía, aspecto este que ubica a Los Sertones en estricto

${ }^{9}$ Euclides da Cunha, Los Sertones, traducción de Estela dos Santos (Caracas: Biblioteca Ayacucho, 1980), p. 3. Toda futura cita de la obra proviene de esta edición. 
paralelo con la obra de Arguedas. De este modo, si en ambas obras el factor geográfico determina la historia, el hombre no tiene capacidad para transformar la naturaleza, sino para agravarla. En «La tierra», por ejemplo, Euclides ve la naturaleza nordestina, portentosa, vacía y catastrófica, bajo la imagen literariạ del desequilibrio y de la muerte:

Las fuerzas que atacan la tierra en su contextura íntima y en su superficie, sin intervalos en su acción demoledora, se sustituyen, con intercadencia invariable, en las dos estaciones únicas de la región.

Se disocian en los veranos quemantes, se degradan en los inviernos torrenciales. Van del desequilibrio molecular, agitándose absurdamente, a la dinámica portentosa de las tormentas. Se unen y se complementán. Y según sea la preponderancia de una o de otra, o el entrecruzamiento de ambas, se modifican los aspectos naturales. Las mismas capas gnésicas, caprichosamente escindidas en planos geométricos, a manera de colmenas..., dan, a veces, la repentina ilusión de hallarse, en aquellos yermos vacíos, ante majestuosas ruinas de castillos... (p. 14).

Como puede apreciarse en esta cita, las palabras científicas «molecular», "gnésico», "geométrico», son pronto agredidas por escenas líricas que desaparecen rápidamente, haciendo que la naturaleza se aleje de la mera descripción científica y adopte las características de la fícción. Pronto, el paisaje es visto bajo un procedimiento encantatorio que ubica a la subjetividad discriminadora del narrador en un punto neutro entre el discurso científico de la realidad y el discurso imaginario de la ficción. Poco a poco, la naturaleza, monstruosa y fantasmagórica, adquiere rasgos antropomorfos, anticipando el destino de sus habitantes:

Las fuertes tempestades que apagan el incendio sordo de las sequías, a pesar de la revitalización que traen, preparan de alguna manera a la región para mayores tragedias. La desnudan brutalmente, exponiéndola cada vez más desprotegida, a los veranos siguientes; la surcan con canales de ríspidos contornos; lá golpean y esterilizan, y cuando desaparecen, la dejan aún más desnuda ante los adustos rayos del sol. El régimen recorre con deplorable intermitencia un círculo vicioso de catástrofes (p. 42).

Pero no es suficiente la descripción humanizada de la naturaleza pará ubicar a la obra en el dominio de la literatura. Al propio tiempo en que la temática de Los Sertones va constriñéndose al análisis de los tipos humanos que pueblan el territorio, se echa a andar el sociologismo biológico que, en «El hombre», controla al «ficcional». Del cruce del portugués, factor aristocrático de la gens brasileña, con el indígena, elemento de descomposición de las viejas razas autóctonas por su rebeldía e ineptitud 
para el trabajo, nace el mestizo, en el que predominan los atavismos de la raza inferior. Factor de degeneración social, el mestizaje, biológicamente inferior, parecería ser el argumento que mejor explique la afinidad de Los Sertones con Pueblo enfermo. Sin embargo, la explicación del brasileño difiere sustancialmente de la del boliviano. Para Euclides, la mezcla de razas es un retroceso porque ante las conclusiones del evolucionismo, el influjo de la raza superior no impide que despunten los estigmas de la inferior. Aunque el mestizaje disímil lleva al autor de Los Sertones a afirmar que no existe un tipo antropológico brasileño, posteriormente matiza el problema cuando introduce la distinción entre el mestizo del litoral y el mestizo sertanejo. El primero es un desequilibrado, un histérico incurable, al que no se puede aplicar terapia alguna que doblegue las tendencias antagónicas de razas sorpresivamente arrimadas, fundidas en un organismo aislado. Al raquitismo de los mestizos neurasténicos del litoral, Euclides opone la descripción del sertanejo, tipo humano sui generis, retrógrado pero no degenerado, capaz de ser elevado a un estadio social superior:

Es natural que grandes poblaciones sertanejas se constituyesen con predominio de sangre indígena tapuia. $\mathrm{Y}$ allí permanecieron olvidadas en un círculo estrecho, durante tres siglos, hasta nuestros días, en un abandono completo, ajenas por completo a nuestros destinos, guardando intactas las tradiciones del pasado. De modo que, ahora, quien atraviesa por esos lugares, observa una uniformidad notable entre quienes los pueblan: rostros y tallas apenas varían en torno de un modelo único, dando la impresión de un tipo antropológico invariable a primera vista diferente del mestizo proteiforme del litoral. Porque mientras éste muestra todos los tonos y ofrece un tipo indefinido, según el predominio variable de sus gentes, el hombre del sertón parece copia de un modelo único, con las mismas características físicas, la misma tez..., cabellos lacios y duros y levemente ondulados. La misma envergadura atlética y los mismos rasgos morales que se traducen en las mismas supersticiones, los mismos vicios y las mismas virtudes.

La uniformidad es impresionante. El sertanejo del Norte es, indudablemente, el tipo de una subcategoría étnica ya constituida (p. 71).

Al afirmar que el sertanejo es una subcategoría étnica superada, producto del aislamiento sociocultural impuesto por condiciones mesológicas que impidieron su degeneración, Euclides se aparta de la visión fatalista de la historia, tan común a las explicaciones que se mueven al interior del evolucionismo. Aceptando al sertanejo como un producto superado del mestizaje, como «la roca viva de nuestra raza», el autor de Los Sertones toca los límites posibles del sociologismo biológico con explicaciones que, aunque contradictorias, muestran ya la crisis del método de observación 
de la realidad. Con frecuencia, Euclides se ve en dificultades para explicar el desempeño innovador de esos mestizos retrógrados. Al mismo tiempo que afirma y reafirma su teoría racial, va mostrando la inventiva increíble de los canudenses, que desarrollan sofisticadas tácticas de guerrilla inadmisibles para la versión europea, supuestamente superior, de una guerra de tipo convencional. Euclides las admira y registra, sin advertir la contradicción en que cae. Aún más, se aparta de aquellas explicaciones simplistas que aceptan la existencia de una conjura monárquica en la que los canudos, supuestamente, reciben apoyo extranjero contra la República, para elaborar una tesis no contemplada por los maestros del evolucionismo: que el aislamiento de los sertanejos ha detenido su inevitable decadencia.

Esta tesis, poco convincente, no cabe duda, representa la tragedia del intelectual ante la falencia del método. En efecto, si el objeto se resiste a la interpretación, resulta imprescindible romper dicha resistencia mediante la racionalización del problema y el reexamen de la propia teoría que pretende explicarlo, modo de proceder que conduciría al autor a reconocer que los métodos experimentales de observación son apenas abstracciones, preconceptos que crean sus propios obstáculos. Incapaz de realizar tal reexamen, de apartarse del etnocentrismo, el máximo de conciencia de Euclides le lleva a plantear la teoría de que el aislamiento de comunidades interrumpe los cruces raciales y da tiempo a que los pobladores superen las desventajas del mestizaje y, por selección natural, se purifiquen. Como indica Costa Lima, Euclides anticipa aquí la teoría de los isolat de Von Weise (1920), ideal de explicación científica que afirma la conducta diferencial de ciertas comunidades que, en determinadas condiciones, retienen a sus grupos sociales bajo modos de comportamiento anacrónico ${ }^{10}$.

$\mathrm{Si}$ al principio de Los Sertones Euclides planteaba la necesidad de instituciones sociales estables que garantizasen la estabilidad étnica capaz de superar el mestizaje, cae luego en cuenta de que las instituciones políticas brasileñas no son más que la fachada que oculta la verdadera inexistencia de la unidad nacional, dándose así el alejamiento de elites que desconocen la existencia de dos naciones: una del litoral, aparentemente civilizada; otra del interior, apegada a formas regresivas de existencia social. El evolucionismo enseña que las leyes del desarrollo de las especies son inviolables, que todo elemento étnico fuerte tiende a subordinar a su destino al elemento más débil. Cuando Euclides observa la realidad brasileña, estas tesis evolucionistas parecen no funcionar: por un lado, el litoral ha demostrado su incapacidad para forjar una civilización; por otro, el aislamiento sertanejo ha logrado desterrar al mestizaje degenerador, pero sus habitan-

${ }^{10}$ Op. cit., p. 228. 
tes distan de ser auténticos ciudadanos. ¿Cómo lograr una nación cuando todo parece haberse estancado en la existencia de formas regresivas de formación social incompatibles con formas superiores de organización? Con este problema no resuelto comienza la tercera parte de la obra, dedicada a la campaña militar.

A la crisis de la explicación evolucionista va a agregarse ahora la crisis militar. En efecto, la impotencia del ejército para resolver el problema bélico concuerda con la impotencia del evolucionismo para explicar los dilemas del país. El fracaso de las sucesivas expediciones contra Canudos muestra que la estrategia europea de la guerra convencional no prospera frente a la táctica guerrillera sertaneja, de extrema movilidad y de conocimiento del terreno. Para destruir al enemigo, resulta entonces necesario imitar sus métodos de lucha, hecho que pone en duda el axioma biológico que orienta toda la explicación. ¿Dónde queda entonces la superioridad biológica de un ejército entrenado y disciplinado por esquemas bélicos europeos? Para Euclides, sin embargo, la apropiación de formas de lucha primitivas no hace necesaria la revisión de los presupuestos etnocéntricos porque, simplemente, el ejército no está en mejores condiciones raciales: su comandante es un epiléptico desequilibrado y los soldados no son más que un conglomerado de «jagunços» mestizos:

... El atributo prominente de nuestros soldados es esa alegría jovial con que se acercan al enemigo. Esos hombres de todos los colores, amalgamas de diversas razas, parece que ante lances peligrosos o emocionales fuertes, por una misteriosa ley de la psicología colectiva, asumían con preferencia los instintos guerreros y la falta de previsión de los salvajes... (p. 204).

Los comentarios de Euclides no logran, sin embargo, explicar el heroísmo sertanejo. De éstos, el autor tiene afirmaciones contradictorias: son fuertes, superiores, inventivos, resistentes, impávidos, pero también son ignorantes, inferiores, anormales, atributos que se extienden a su líder, Antônio Conselheiro, y a la aldea donde viven. Lo que el etnocentrismo de Euclides no puede concebir es que los sertanejos luchan y mueren en defensa de su organización social, política, económica y familiar. Así, lo máximo que la conciencia de Euclides puede admitir es la plasmación estética de la selección natural del sertanejo:

Se detuvieron a un costado de las tiendas del escuadrón de caballería... Entonces, por primera vez, se vio, globalmente, la población de Canudos. $Y$ aparte de las variaciones impuestas por el sufrimiento soportado, sobresalía una uniformidad llamativa en las fisonomías. Muy raramente un blanco o un negro puro... Predominaba el pardo, mezcla 
de «cafre», portugués y «tapuia»: caras bronceadas, cabellos lacios, duros o ensortijados, cuerpos desaliñados, y aquí y allí, el perfil correcto denunciando el elemento superior del mestizaje (p. 380).

Y esta alteración del mestizaje, por donde Euclides desvía la interpretación de la lucha sertaneja, muestra también que en Los Sertones el control que los postulados etnocéntricos ejercen sobre los hechos narrados no puede ser superado.

\section{III}

La visión trágica de Los Sertones opera desde un doble punto de vista: como principio selectivo de la mimesis que permite el equilibrio de la obra entre el discurso cientificista y el discurso imaginario. Pero este principio de organización narrativa cede ante la presencia subalterna, luego preponderante, de otra forma de tragedia que nada tiene que ver con la mimesis: la imposibilidad de que el esquema teórico evolucionista pueda explicar las contradicciones de la realidad observada. Esta segunda situación trágica obliga al autor a postular su tesis del aislamiento sertanejo, la misma que toca los límites del evolucionismo, pero que no conduce a otro esquema teórico. Incapaz de romper con el etnocentrismo, la visión trágica de Euclides da Cunha se aparta, sin embargo, de la relación mecanicista entre hombre y medio ambiente a que lleva el fatalismo de Alcides Arguedas, expuesto en los términos siguientes:

Herencia, incultura, pereza, pobreza, he aquí, en suma, sintetizadas las verdaderas y profundas causas del malestar de nuestros países.

Todas estas causas pueden resumirse en dos: el medio geográfico y la raza.

Somos producto del pasado, porque nada no engendra nada y las herencias taradas se pagan, fatal e inexorablemente, con una vida lánguida y miserable... ${ }^{11}$

El medio geográfico, determinante en la constitución de los agrupamientos humanos, y las razas, que determinan la psicología colectiva, son, para el mecanicismo de Arguedas, los ejes a partir de los cuales se dan las denuncias, las acusaciones y los prejuicios que muestra Pueblo enfermo.

it Alcides Arguedas, Pueblo enfermo, 3. ${ }^{\mathrm{a}}$ ed. (Santiago de Chile: Ediciones Ercilla, 1937), pp. 180-181. Toda futura cita de la obra proviene de esta edición. 
La acción del medio geográfico sobre el hombre tiene, en Arguedas, un carácter simplemente descriptivo. Así, la acción puramente mecánica e inmodificable que el altiplano ejerce sobre el indio lleva el sello de la fatalidad:

La pampa y el indio no son sino una sola entidad. $\mathrm{El}$ aspecto físico de la llanura, el género de ocupaciones, la monotonía de éstas, ha moldeado su espíritu de manera extraña. Nótese en el hombre del altiplano la dureza del carácter, la aridez de sentimientos, la absoluta ausencia de afecciones estéticas. El ánimo no tiene fuerzas para nada, sino para fijarse en la persistencia del dolor. Llégase a una concepción siniestramente pesimista de la vida. Todo lo que nace del hombre es pura ficción. La condición natural de éste es ser malo, y también de la naturaleza... (p. 35).

Al comentar esta cita de Pueblo enfermo, un sociólogo boliviano contemporáneo afirma que, de seguirse el curso de la argumentación, se llegaría a la absurda conclusión de que para cambiar la "ética de la tristeza» habría que cambiar la geografía en que se funda, poniendo a dos metros de altura la meseta de cuatro mil ${ }^{12}$. Sólo así el habitante andino dejaría de estar condenado a la angustia por una eternidad. Lo cierto es que el determinismo mecanicista entre hombre y medio ambiente, que luego se hace extensivo a la explicación del atraso de la República por la accidentada latitud geográfica del territorio, ignora los ingredientes históricos esenciales de la sociedad, y pasa por alto su sistema económico y social. El hombre ha perdido entonces la capacidad de transformar la naturaleza. Esto puede comprobarse también en el desequilibrio profundo que Arguedas ve entre el territorio y la calidad de su población. Por eso no hay la estabilidad y la armonía que exige todo progreso. Si Europa es una vasta llanura uniforme, América es un suelo agreste y complicado. El medio geográfico condiciona el desarrollo.

En cuanto a la gravitación de la raza sobre la composición histórica nacional y su psicología colectiva, ésta se coloca al margen de los intereses de clase, de las fuerzas económicas y de la demografía. Aunque el etnocentrismo de Pueblo enfermo no tiene por fuente al evolucionismo de Spencer ni a la lucha de razas que Los Sertones retoma de Gumplowicz y los darwinistas, Arguedas, temperado por el espíritu francés y la psicosociología leboniana, mira también con repugnancia al mestizaje. En efecto, de los aspectos negativos de la raza ibera (belicosidad, ensimismamien-

12 Juan Albarracín, «Las tesis de Pueblo enfermo», en Alcides Arguedas, ed. de Mariano Baptista Gumucio (La Paz-Cochabamba: Editorial Los Amigos del Libro, 1979), p. 273. 
to, vanidad, nepotismo, rimbombante oratoria) y de la raza indígena (sumisión, falta de iniciativa, inclinación a la mentira, al engaño, a la hipocresía y a la deslealtad) nace la raza mestiza, incapaz de constituirse en factor de unidad nacional y cuyo tipo más representativo es el cholo. Político, militar, abogado o cura, este tipo humano, pequeño de espíritu, jamás se pregunta si sus actos son o no morales, armoniosos con el bienestar general. Híbrido desequilibrado, al igual que el mestizo del litoral en Los Sertones, sus sentimientos políticos oscilan entre el amor y el odio; liberado de la ignorancia, puede ser incrédulo hasta la candidez o escéptico hasta la ferocidad. En líneas generales, Bolivia ha evolucionado en el sentido inverso a toda asociación humana por el predominio de la modalidad mestiza, la que, desplazando al núcleo racial ibero, ha hecho que éste pierda sus cualidades para heredar las de la raza sometida.

Es la raza mestiza la que, para Arguedas, ha concluido por desalojar a la raza superior, lo que ahora se revela en las manifestaciones bajas y egoístas de un pueblo enfermo. De este modo, el enorme peso psicológico de esta argumentación racista limita no sólo el modo de observación de la realidad, sino también las conclusiones a las que llega. Por eso los caudillos, que expresan las cualidades y defectos de su pueblo, aparecen, al final de la obra, como arquetipos de sus grupos étnicos: unos leales pero débiles (los caudillos letrados), otros fuertes pero desleales e hipócritas (los caudillos bárbaros). Esta forma maniquea de ver las cosas, cuyo barómetro no va más allá de la mayor o menor cantidad de sangre indígena, se muestra particularmente en el influjo de la raza sobre la psicología de dos grupos regionales: los paceños y los cochabambinos.

Si de los paceños Arguedas dice que la gran masa de sangre aymara y las pocas gotas de sangre castellana han hecho que éstos sean mentirosos y retraídos, es en su análisis de la psicología del pueblo cochabambino donde se observa la oposición central de la obra, entre razón e imaginación. Es claro que Arguedas se ubica al lado de la primera y desdeña la imaginación como la virtud "femenina» de este pueblo quechua, soñador pero nada emprendedor:

Lo que primero se observa en el pueblo cochabambino desde el primer momento en que se le estudia es un desborde imaginativo. No sé si por la diafanidad de su cielo, por la lujuriante exuberancia de su campiña o por su alimentación, en Cochabamba nacen las ideas generosas, grandes y caballerescas. Lo que dice Le Bon de las muchedumbres en general se puede aplicar a Cochabamba en particular: es la más femenina de las muchedumbres bolivianas.

Allí la imaginación prima en desborde impetuoso e incontenible, una imaginación robusta, varia en tonalidades, flexible, armoniosa; pero su 
excesivo desarrollo la hace cometer errores de toda índole y, en particular, errores de apreciación, pues toda imaginación viva presenta las cosas en distinto aspecto, predisponiendo así a la alucinación y al engaño. Pero una imaginación viva proviene de un sentimiento vivo también, y de ahí un estado particular propio a los meridionales, inclinados, por temperamento, a rendir tributo a lo fantástico, a lo que pasa de la realidad. $Y$ esto que no es cualidad apreciable, sino, al contrario, vicio, tiene la particularidad de propagarse con gran facilidad y penetrar hasta en pueblos e imaginaciones secas, meditativos y observadores. Si se fuera a analizar, por tanto, la génesis de nuestro estado colectivo, que es de alucinación o fantasía, veríamos que ha nacido en regiones de poderosa fecundidad y se ha propagado luego a los menos fecundos, por ser un fenómeno conocido el de que toda alucinación se transmite por la fuerza de sugestión y pasa de un individuo a otro, de un grupo a otro grupo, aunque sean de temperamento desigual (pp. 69-71).

De esta larga cita no nos interesa saber si Arguedas incurrió o no en un error de concepto cuando opina que el cochabambino es imaginativo, problema que Miguel de Unamuno corrige en su artículo «La imaginación en Cochabamba» ${ }^{13}$, sino resaltar el otro fenómeno, más a tono con nuestro trabajo, de la manera recelosa con que el escritor boliviano observa al discurso imaginario, definiéndolo como algo irreal y falso, capaz de perturbar el buen entendimiento de las cosas. Lo que Arguedas nos dice es que los desbordes de la imaginación deben ser controlados por la razón, la única capaz de corregir la alucinación y la fantasía. Definiendo a la imaginación como «lo que pasa de la realidad», como la facultad de representar como si fuera real lo que no lo es, aquélla no favorece al desarrollo de la capacidad de observación, y se aleja, por ende, de los criterios de verdad que priman en el discurso racional, armonioso con el bienestar general. De este modo, este discurso moralizador no opta por la imitación de modelos de elocuencia y sabiduría, propios al lenguaje ornamental de la fícción, sino por criterios apegados a la ceñida observación de la realidad. Se trata, pues, de un racionalismo ético que, combinando nuevamente la verosimilitud con el decoro, purga a la «imaginación armoniosa» de todo «vicio» que amenace o ponga en duda el honesto entendimiento de la realidad.

El discurso moralizador de Pueblo enfermo busca corregir la amplia gama de deformaciones imaginativas que hacen que el boliviano, condicionado por su medio ambiente, exprese sus sentimientos en un lenguaje que percibe erróneamente sólo lo enorme, lo grandioso, y que, por los excesos del verbo, olvida o deja de lado las ideas. Cuestión de pura visuali-

${ }^{13}$ Miguel de Unamuno, Contra esto y aquello, 2. ${ }^{a}$ ed. (Buenos Aires-México: Espasa-Calpe Argentina, S. A., 1945), pp. 34-41. 
dad, la imaginación hace que la razón se torne en vana fórmula. Y puesto que se trata de progresar en el aprendizaje y armonizar las actividades en pos del bienestar general, la moral de Pueblo enfermo justifica así su esencia pragmática. Moral iluminada por la razón, aquélla exige que lo bueno, lo racional, lo verdadero, controle lo bello, lo estético, lo imaginario. Por eso Arguedas, al referirse a la función del intelectual, plantea en los siguientes términos el «estatuto del escritor»:

... Porque ya las pasiones han dado mucho de sí y nuestros poetas y escritores, si verdaderamente quieren hacer algo original, tienen que crear y no imitar... Aún más: tienen que copiar, pues su error consiste en dejar a la naturaleza intacta, virgen, y sólo fijarse y escudriñar el fondo de sus sentimientos para presentarlos con vigor, aunque desprovistos de espontaneidad. Y así —insisto- no se hace arte ni se engendra una literatura. Su deber es desentrañar la psicología del grupo. La mejor obra literaria será, por tanto, aquella que mejor ahonde el análisis del alma nacional y la presente en observación intensa, con todas sus múltiples variaciones (p. 246).

Intentando corregir las pasiones, es decir, las deformaciones imaginativas de escritores y poetas, Arguedas tiene controlada la creación literaria. $\mathrm{La}$ función del escritor sería entonces no imitar modelos que lo lleven a la falsa ornamentación del lenguaje, sino crear, reproducir, copiar lo verdadero. De este modo, la postura pragmática del control del «ficcional» gira alrededor de los principios de la verosimilitud y del decoro. Por eso prima en Arguedas la observación intensa, exterior, tan propia del discurso pragmático-cotidiano que, inclinándose hacia lo perceptible, desdeña lo imaginario y neutraliza la subjetividad. En suma, si la función del escritor es la búsqueda de la verdad del «alma nacional», Arguedas parece no ver las diferencias entre el ensayo sociológico y la ficción. Por eso Pueblo enfermo, una prolongación de Alma boliviana, ensayos periodísticos publicados por el autor entre 1905 y 1906, sólo puede ser entendido como una impugnación pragmática de la realidad boliviana, la misma que también aparece tanto en Arguedas novelista como en el memorialista.

Si se leen juntos Pueblo enfermo y Raza de bronce (1919), con el que se inicia la novela indigenista en Hispanoamérica, la mera comparación de los títulos produce en el lector la sensación de dos libros contrastantes, opuestos. Frente a la metáfora de la «enfermedad» (debilidad, degeneración, incapacidad, ineficacia), la metáfora racial del «bronce» (fuerza, resistencia, poder, salud). Sin embargo, y como un artículo reciente sobre la novela de Arguedas así lo muestra, el examen de los dos libros obliga a corregir la observación inicial porque Pueblo enfermo controla todos los 
aspectos que la novela desarrolla dramáticamente por medio de personajes, situaciones y diálogos ${ }^{14}$. Así, lo broncíneo de la raza no remite a una fuerza vivificante y saludable, sino más bien a la rudeza bestial que, en correspondencia con el hosco paisaje andino, la psicología de Arguedas asigna a la raza aymara. De Raza de bronce no es la condena étnica ni la explotación inhumana del indio lo que interesa aquí resaltar, sino la manera en que el escritor vuelve a controlar la ficción.

Entre los personajes no indios de la novela, Suárez, indagador de las costumbres indígenas, es el único que tiene cierto valor positivo. Es casi un segregado de su grupo social, un honesto intelectual que lamentablemente cultiva la poesía y escribe cuentos fantásticos. Esta faceta del intelecto del personaje se le antoja ridícula a Arguedas, a quien llama «ingenuo poeta enamorado». Y esta actitud crítica del novelista puede ser vista explícitamente en muchos pasajes de la obra. De su personaje, Arguedas dice:

Le faltaban hábitos de observación y de análisis, sin los cuales es imposible producir nada con sello verazmente original y, sobre todo, le faltaba cultura. Saturado hasta los tuétanos de ciertas lecturas modernistas, estaba obsesionado con encantadas princesas de leyendas medievales, gnomos, faunos, sátiros... Soñaba, pues, el poeta ${ }^{15}$.

La posición de Arguedas ante el poeta modernista es terminante. A éste se le ataca porque el tema de su poesía se evade de la realidad; porque provoca una actitud mental que, aun en el espíritu de buena voluntad con el que el personaje pretende acercarse a los hechos, deforma su capacidad de análisis y le aleja de la verdad. Observación y análisis son, pues, los valores pragmáticos que el ensayista, ahora novelista, exige de todo escritor. Pero son estos mismos modos de observación de la realidad que, literalmente hablando, hacen de Raza de bronce una pintura exterior de paisajes y de personajes, de muy limitada introspección. Novela epidérmica, la de Arguedas ve bien los rasgos fisonómicos de la persona cuyo retrato traza, de los cuales induce luego la fisonomía moral del "yo» social, pero no llega a calar el «yo» profundo escondido tras la máscara. De manera muy similar a lo que ocurre en Pueblo enfermo, al pintar el medio ambiente y las razas que determinan la psicología colectiva, el autor reproduce con gran fidelidad y verismo los hechos, pero no llega a penetrar en el sentido de ellos. Y porque en Arguedas el sociólogo determinista prima

${ }^{14}$ Rodolfo A. Borello, «Arguedas: Raza de bronce», en Cuadernos Hispanoamericanos, 417 (marzo 1985), p. 113.

${ }^{15}$ Alcides Arguedas, Raza de bronce, 2." ed. (Buenos Aires: Editorial Losada, S. A., 1957), p. 208. 
sobre el ensayista y el novelista, en todas las facetas del escritor boliviano la razón pragmática se antepone y controla al hecho «ficcional». ¿Qué decir de Arguedas memorialista?

Carlos Medinaceli ha visto muy claramente que no resulta paradójico que al Diario íntimo, de Arguedas, escrito en 1943, pocos años antes de su muerte, le falte intimidad, es decir, subjetividad ${ }^{16}$.

Género que se desentiende de los controles de cánones y reglas, el diario permite la más desenvuelta manifestación de la originalidad, de la introspección y del autoanálisis. En efecto, el diario, género literario que se presta a la confidencia íntima, no se sujeta a cánones y reglas determinadas de composición y permite al escritor verter libremente la esencia más propia de su ser. Arguedas señala la influencia de Amiel en la composición de su Diario, pero ni en su espíritu ni en su mentalidad el escritor boliviano parece haber recibido el influjo del escritor ginebrino. Observa Carlos Medinaceli la profunda diferencia entre ambos, con juicios muy parecidos a los aquí empleados para explicar el control de lo imaginario y de la subjetividad: «... la educación, la de Arguedas, antes que la hegeliana de Amiel, ha sido la del riguroso positivismo experimentalista y ametafísico del siglo de la mecánica y la sociología materialista que viniera a acentuar su innata propensión objetivista, y a ello hay que agregar la índole de trabajos a que se ha consagrado la novela realista, la sociología y la historia, que demandan como método esencial la menor dosis de subjetivismo y la mayor objetividad» ${ }^{17}$. Luego Medinaceli añade: «De ahí que, aunque hubiera tomado de Amiel el gusto por el "Diario", en este su libro de "confesiones", que debieran ser una entrañada intimidad confidencial o de una ensimismada introspección analítica, no encontramos nada de eso, sino, al contrario, reproducción objetiva de hombres y paisajes, pero no el paisaje como un estado del alma ni el alma como un paisaje interior» ${ }^{18}$.

Originalidad, introspección y autoanálisis son, pues, los aspectos que le faltan al diario de Arguedas. Psicólogo objetivista, el escritor boliviano sigue siendo en sus memorias íntimas el sociólogo determinista y el historiador moralista. Si en Pueblo enfermo el tema era la patria, es decir, el proceso de la nacionalidad, ahora, en el Diario, es el proceso del escritor. Ha cambiado de tema, mas no de mentalidad. No será entonces vano concluir que para Arguedas, al igual que para Euclides, el control del «ficcional» reposa en un cierto elogio de la ciencia. Por eso la primacía del dis-

${ }^{16}$ Carlos Medinaceli, La inactualidad de Alcides Arguedas (La Paz-Cochabamba: Editorial Los Amigos del Libro, 1972), pp. 60-67.

${ }^{17}$ Op. cit., pp. 65-66.

${ }^{18}$ Ibíd., p. 66. 
curso cientificista domina al discurso imaginario, hecho que se ve en Los Sertones, e impide el desarrollo de la subjetividad, como en las diferentes facetas de la obra de Arguedas. Dominada así la ficción literaria por la temática perceptiva del discurso racional pragmático, aquélla se aleja del verdadero sentido de la mimesis: no copiar lo verosímil, sino descubrir lo diferente, la dispersión del sentido. 